\title{
Clinicopathological Evaluation of Acute Leukemias in a Tertiary Care Hospital: A Cross-Sectional Study
}

\author{
Gayatri N. PATEL ${ }^{1} \mathbb{D}$, Rashmi GUDUR ${ }^{2} \mathbb{D}$, Anand GUDUR ${ }^{2} \mathbb{D}$, R. M. OSWAL ${ }^{1}$, Sujatha KANETHKAR ${ }^{2}$
}

Department of ${ }^{1}$ Pathology, ${ }^{2}$ Oncology, Krishna Institute of Medical Sciences (Deemed to University), MAHARASHTRA, INDIA

\section{ABSTRACT}

Objective: Acute Myeloid Leukemia (AML) and Acute Lymphoblastic Leukemia (ALL) are clinically and biologically diverse phenotypic diseases amongst hematological malignancies. The current study objectives were to diagnose and classify cases of $\mathrm{AL}$ as per revised $4^{\text {th }}$ edition of WHO 2016 classification of AL's and study their clinicopathological profiles.

Material and Method: This cross-sectional, observational study included 68 patients, diagnosed with AL were recruited. Diagnosis was based on peripheral blood smear examination, bone marrow aspiration, flowcytometry, and cytogenetic and molecular studies.

Results: Sixty-eight cases of AL were diagnosed in a period of 2 years, where 25 cases were of ALL and 43 cases were of AML. In the subclassification of AML as per WHO 2016, 20 cases were of AML, RGA, 21 cases were of AML, NOS, and 2 cases were of AML, MRC. In AML, RGA, APL with PML-RARA positive cases were 10 out of 20 cases, AML with (8;21) RUNX1-RUNX1T1 were 7/20 cases; there were two cases of AML with mutated NPM1 gene and one case of AML with biallelic mutation of CEBPA. In AML, NOS subcategory AML with maturation was more common with 9/21cases. In subcategory of ALL, B-ALL was more common than T-ALL. B-ALL, NOS was more common than B-ALL, RGA and we had 1 case of NK cell Leukemia.

Conclusion: The application of revised 4th edition WHO 2016 classification confers uniformity in reporting acute leukemia cases that aids in the treatment by using targeted therapies and helps in the prediction of prognosis. The WHO classification for acute leukemias is very objective, therapy oriented and the need of the hour.

Keywords: Acute myeloid leukemia, WHO classification 2016, Flow cytometry, Cytogenetics, Molecular study

\section{INTRODUCTION}

Acute leukemias (AL) constitute a heterogeneous group of hematological malignancies, characterized by an uncontrolled proliferation of hematopoietic cells that infiltrate into the bone marrow and blood (1).

Acute myeloid leukemia (AML) and acute lymphoblastic leukemia (ALL) are the two main types of AL, with a global prevalence of 3-4 and 0.4-2 per 100,000 individuals, respectively (2-4). The annual incidence in India is estimated to be 4.3 and 1.4 per 100,000 individuals for AML and ALL, respectively $(5,6)$. AML is more prevalent in adults and ALL in children (7).

The FAB classification system was proposed in 1976 for classifying these diseases in order to treat them as per their biologic behavior. However, it had its own set of drawbacks as it was based on morphology alone and led to subjective errors (8). This subjectivity in diagnosis was eliminated by the WHO classification system, proposed in 1999 and revised in 2001, 2008, and 2016 (published in 2017). The WHO (2016) classification system was evolved to improve the objectivity and reproducibility by additionally utilizing the cytogenetic, molecular, cytochemical, and immunologic characteristics for an integrated diagnosis $(9,10)$. This has greatly contributed to the determination of differential diagnosis and prognosis of leukemic proliferations, facilitating targeted treatment as per their pathologic behavior. This includes management of recognizable genetic lesions, stem cell transplantation as well as immunotherapy such as treatment directed at specific cluster differentiation (CD) markers (11). The regular revisions of $\mathrm{AL}$ classifications have given rise to a constant need to study these pathologies in order to upgrade the management strategies.

The present study aims to diagnose and classify AL cases according to the WHO Classification of Tumors of Hematopoietic and Lymphoid Tissues, 2016, revised 4th edition and study their clinicopathological profiles (9).

\section{MATERIALS and METHODS}

This cross-sectional, observational study was conducted at the Department of Pathology, in a tertiary teaching hospital 
in India, from June 2017 to May 2019, after obtaining ethical clearance from the Institutional Review Board (protocol number: 031/2017-18, Date: 23.11.2017).

In all, 68 patients diagnosed with AL (AML and ALL) as per the WHO Classification of Tumors of Hematopoietic and Lymphoid Tissues, 2016, revised 4th edition criteria, irrespective of age and gender, were recruited into the study after obtaining written informed consent from them (or their legal guardians in case of minor patients) (6). AL cases without cytogenetic studies or advanced ancillary techniques were excluded from the study. Patients were examined for pallor, fever, generalized weakness, bony tenderness, petechiae, ecchymosis, and gum bleeding. Presence of hepatomegaly, splenomegaly, and lymphadenopathy was also recorded. Ultrasonography (USG) was performed where necessary. Morphologic dysplasia, cytogenetic abnormalities, and discontinuation of chemotherapy due to low blood cell count were considered as unfavorable prognostic factors.

\section{Hematological Investigation}

This included estimation of hemoglobin ( $\mathrm{Hb}$ ) levels, total leukocyte count (TLC), differential leukocyte count (DLC), and platelet count, using the Sysmex XT-1800i (XT-1800i, Sysmex Corporation, Kobe, Japan). Peripheral venous blood samples were collected in ethylenediaminetetraacetic acid (EDTA)-anticoagulated vacutainers. Peripheral smears were made, stained with the Romanowsky Leishman stain, and studied in detail for morphology. In cases of leukopenia, buffy-coat smears were prepared and stained with the Leishman stain and examined for the presence of blast cells. A provisional diagnosis was made and ancillary studies performed.

\section{Immunophenotyping}

All cases underwent flow-cytometric analyses using $\mathrm{BD}$ FACSCanto $^{\mathrm{mm}} \mathrm{II} / \mathrm{FACSDiva}^{\mathrm{m}}$ 6-color flowcytometry (BD Biosciences, Becton, Dickinson, and Company, New Jersey, USA), molecular studies using nested/reverse transcriptase polymerase chain reaction (PCR), and cytogenetic studies using fluorescence in-situ hybridization (FISH).

\section{Bone Marrow Aspiration Study}

This was performed on all patients under aseptic conditions and local infiltration anesthesia with $3 \mathrm{cc}$ of $2 \%$ lignocaine. Bone marrow aspiration was performed from the posterior superior iliac spine using Salah's aspiration needle. Smears were prepared, air dried, and stained with the Giemsa stain. If the marrow particles were not visibly present in the aspirate, it was centrifuged and the smears prepared accordingly. The smears were meticulously examined for cellularity, predominant series, myeloid:erythroid ratio, erythroid series cells, myeloid series cells, lymphocytes, plasma cells, megakaryocytes, blast cells, atypical cells, mitosis, iron stores, and parasites. At least 500 cells were counted to obtain the myelogram.

\section{Bone Marrow Trephine Biopsy}

Indicated only when a dry tap was obtained or the aspirate was inadequate for diagnosis (6 out of 68 cases). Bone marrow was obtained from the posterior superior iliac spine using a Jamshidi ${ }^{\text {tw }}$ needle (BD Biosciences, Becton, Dickinson, and Company, New Jersey, USA) under aseptic conditions and local infiltration anesthesia with $2 \%$ lignocaine. The biopsy needle was introduced in the bone cortex with a rotatory movement and gently advanced after removing the stylet. An optimal 1-2 cm long biopsy sample was obtained in its maximum diameter, placed in $10 \%$ formalin fixative, decalcified in 14\% EDTA solution, submitted for routine paraffin processing, and stained with hematoxylin and eosin for further examination.

\section{Statistical Analysis}

The data was collected, compiled, and analyzed using SPSS version 20 software (IBM Corp., released 2011, IBM SPSS Statistics for Windows, Version 20.0. Armonk, NY: IBM Corp.). Categorical variables were expressed in terms of frequencies and percentages.

\section{RESULTS}

The present study included 68 cases of AL, of which 43 (63.24\%) were diagnosed with AML and 25 (36.76\%) with ALL. Covering an age range of 10-70 years, the mean age of the included participants was $37.07 \pm 21.15$ years, with a slight male predominance $(\mathrm{M}: \mathrm{F}=1.7: 1)$. The average age was $48.16 \pm 16.18$ years for the AML cases and 8.28 \pm 13.85 years for the ALL cases. Both were more common in males (M:F = 1.5:1 in AML; 2.1:1 in ALL). The frequency distribution of different types of AL is described in Table I. The frequency distribution of the clinical features of AL is shown in Table II. Fever was the most common presenting symptom (91.81\%) followed by generalized weakness $(80.88 \%)$. The most common presenting sign was pallor $(94.19 \%)$ followed by splenomegaly $(80.88 \%)$. Table III summarizes the hematological characteristics of these subjects. Anemia ( $\mathrm{Hb} 7.2 \mathrm{~g} \%$ ), leukocytosis $\left(>100,000 / \mathrm{mm}^{3}\right)$, and thrombocytopenia $\left(<40,000 \mathrm{~mm}^{3}\right)$ were seen in all the cases, with a low neutrophil count (7.6\%) and an increased peripheral blast cell count of $>20 \%$ (reaching an average of 63\%). Granulocyte precursor cells like myelocytes, metamyelocytes, promyelocytes, 
Table I: Frequency distribution of different types of acute leukemias

\begin{tabular}{|c|c|c|}
\hline Type of Acute Leukemia & No. of subjects & Percentage (\%) \\
\hline ALL & 25 & 36.76 \\
\hline 1) T-ALL & 6 & 76 \\
\hline 1a) T-ALL NOS & 5 & 83.3 \\
\hline 1b) T-ALL NK & 1 & 16.7 \\
\hline 2) B-ALL & 19 & 24 \\
\hline 2a) B-ALL NOS & 15 & 78.9 \\
\hline 2b) B-ALL RGA & 4 & \multirow{3}{*}{21.1} \\
\hline (i) B-ALL with $\mathrm{t}(12 ; 21)(\mathrm{p} 13 ; \mathrm{q} 22)-\mathrm{TEL}$ AML1(ETV6 RUNX1) & 3 & \\
\hline (ii) B-ALL with $\mathrm{t}(9 ; 22)(\mathrm{q} 34 ; \mathrm{q} 11.2)-\mathrm{BCR}$ ABL1 & 1 & \\
\hline AML & 43 & 63.24 \\
\hline 1) AML - RGA & 20 & \multirow{5}{*}{46.51} \\
\hline 1a) AML with t(8;21)(q22;q22.1) RUNX1 RUNX1T1 & 7 & \\
\hline 1b) APL with PML RARA & 10 & \\
\hline 1c) AML with mutated NPM1 & 2 & \\
\hline 1d) AML with biallelic mutations of CEBPA & 1 & \\
\hline 2) AML - MRC & 2 & 4.66 \\
\hline 3) AML - NOS & 21 & \multirow{7}{*}{48.83} \\
\hline 3a) AML with minimal differentiation & 2 & \\
\hline 3b) AML without maturation & 2 & \\
\hline 3c) AML with maturation & 9 & \\
\hline 3d) Acute myelomonocytic leukemia & 3 & \\
\hline 3e) Acute monoblastic leukemia & 4 & \\
\hline 3f) Pure erythroid leukemia & 1 & \\
\hline
\end{tabular}

AML: Acute myeloid leukemia, ALL: Acute lymphoblastic leukemia, NOS: Not otherwise specified, NK: Natural killer cell, RGA: Recurrent genetic abnormality, MRC: Myelodysplasia-related changes, APL: Acute promyelocytic leukemia.

Table II: Frequency distribution of clinical features of acute leukemias

\begin{tabular}{lcccc}
\hline Clinical features & AML $(\mathbf{n}=\mathbf{4 3})$ & ALL $\mathbf{n}=\mathbf{2 5})$ & Total $(\mathbf{n}=\mathbf{6 8})$ & Percentage (\%) \\
\hline Fever & 40 & 22 & 62 & 91.81 \\
\hline Generalized weakness & 35 & 20 & 55 & 80.88 \\
\hline Bone pain & 24 & 15 & 39 & 57.35 \\
\hline Loss of appetite and weight & 14 & 13 & 27 & 39.71 \\
\hline P/R bleed & 12 & 3 & 15 & 22.06 \\
\hline Epistaxis & 9 & 5 & 14 & 20.59 \\
\hline Breathlessness & 10 & 3 & 13 & 19.19 \\
\hline Gum bleeding & 11 & 0 & 11 & 16.18 \\
\hline Ecchymosis & 4 & 5 & 09 & 13.24 \\
\hline Convulsions & 1 & 1 & 02 & 2.94 \\
\hline Pallor & 42 & 22 & 64 & 94.19 \\
\hline Splenomegaly & 34 & 21 & 55 & 80.88 \\
\hline Hepatomegaly & 34 & 18 & 52 & 76.47 \\
\hline Lymphadenopathy & 5 & 9 & 14 & 20.59 \\
\hline
\end{tabular}

AML: Acute myeloid leukemia, ALL: Acute lymphoblastic leukemia, P/R: Peripheral. 
and promonocytes were increased in cases of AML. The immunophenotyping findings in these AL cases are detailed in Table IV. Table V presents the distribution of AL cases according to their prognosis. The comparative results revealed that the prognosis was more on the unfavorable side for all the leukemia types, and all the patients having unfavorable prognosis succumbed to their illness within 6-9 months after diagnosis. The histological findings from the peripheral smear and bone marrow aspirate are presented in Figure 1A-J.

Table III: Mean values of hematological parameters in cases of acute leukemia

\begin{tabular}{lccc}
\hline Hematological parameters & AML & ALL & AL \\
\hline $\mathrm{Hb}(\mathrm{g} \%)$ & $7.09 \pm 2.17$ & $7.53 \pm 3.03$ & $7.25 \pm 2.51$ \\
\hline $\mathrm{TLC}\left(/ \mathrm{mm}^{3}\right)$ & $97317.06 \pm 81204.11$ & $112326.8 \pm 114817.65$ & $102835.35 \pm 94387.92$ \\
\hline Blast $(\%)$ & $61 \pm 25.72$ & $68.36 \pm 12.01$ & $63.76 \pm 21.89$ \\
\hline Platelet count $\left(/ \mathrm{mm}^{3}\right)$ & $36674.41 \pm 27766.64$ & $45480 \pm 25314.88$ & $39911.76 \pm 27039.901$ \\
\hline Neutrophils $(\%)$ & $9.21 \pm 9.104$ & $4.84 \pm 4.36$ & $7.6 \pm 7.95$ \\
\hline Lymphocytes (\%) & $7.67 \pm 6.22$ & $22.2 \pm 9.19$ & $13.01 \pm 10.21$ \\
\hline Eosinophils (\%) & $1.51 \pm 2.26$ & $1.12 \pm 1.16$ & $1.37 \pm 1.93$ \\
\hline Monocytes (\%) & $1.53 \pm 3.54$ & $0.48 \pm 1.29$ & $1.15 \pm 2.95$ \\
\hline Basophils (\%) & - & - & - \\
\hline Band forms (\%) & $1.3 \pm 2.55$ & $0.48 \pm 0.96$ & $1.75 \pm 3.44$ \\
\hline Metamyelocytes (\%) & $2.42 \pm 3.92$ & $0.6 \pm 2.02$ & $2.94 \pm 6.07$ \\
\hline Myelocytes (\%) & $3.91 \pm 6.44$ & $1.28 \pm 5.08$ & $20.01 \pm 15.74$ \\
\hline Promyelocytes (\%) & $20.78 \pm 19.08$ & $0.72 \pm 2.87$ & $23 \pm 0.0$ \\
\hline Promonocytes $(\%)$ & $23 \pm 0.0$ & $0 \pm 0.0$ &
\end{tabular}

AML: Acute myeloid leukemia, ALL: Acute lymphoblastic leukemia, Hb: Hemoglobin, TLC: Total leukocyte count.

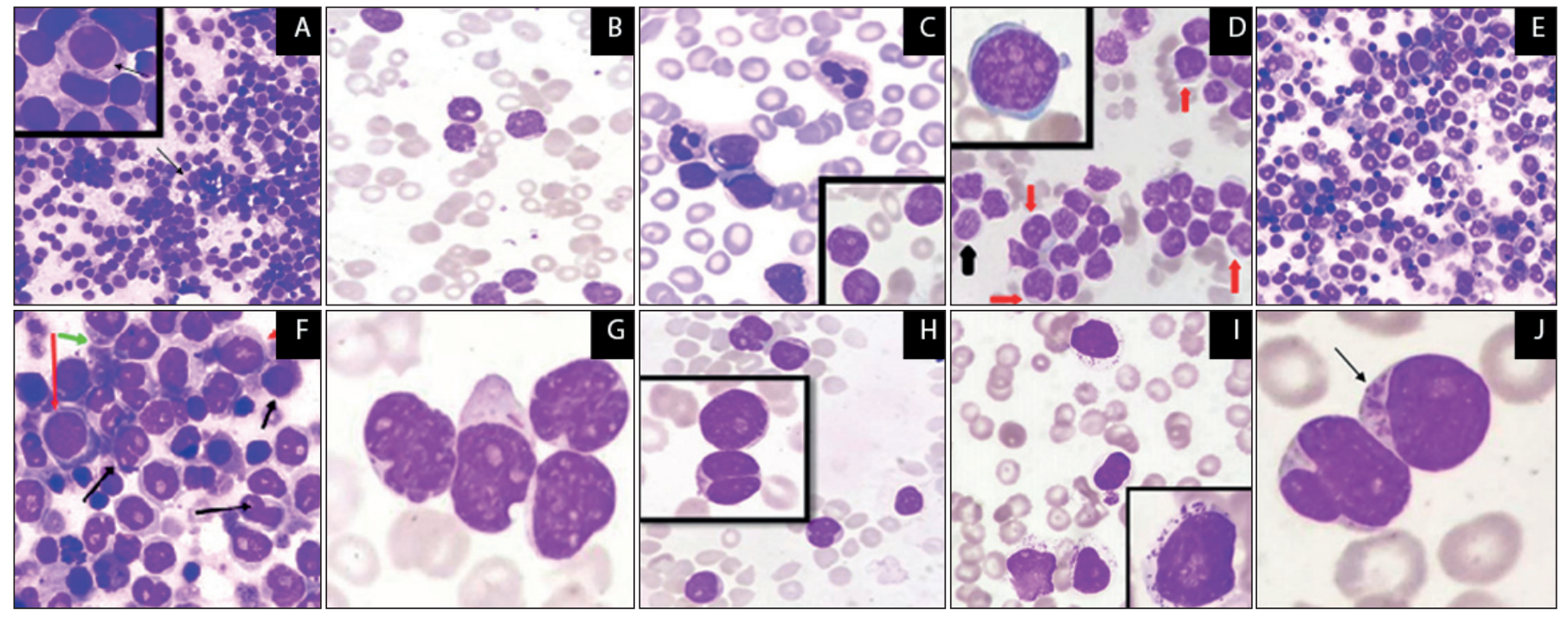

Figure 1: A) Hypercellularity in BMA with blast cells, Arrow shows blast cell with Auer rod in AML. B) PBS Showing large blasts with variable $\mathrm{N}$ :C ratio and scant-to-moderate amount of basophilic cytoplasm, absence of maturing granulocytes indicate AML-NOS. C) PBS showing large blasts features with matured nuclei favoring AML-NOS with maturation. D) PBS Showing severe leukocytosis with blasts features favoring AML-NOS (Black arrow showing Monoblasts ; Red arrow showing Promonocytes). E) BMA showing case of AMLNOS. F) BMA of AML-NOS showing neutrophilic precursors (Black arrow showing myelocytes ; Red arrow showing Promonocytes; green arrow shows auer rod myeloblast). G) PBS of APL showing bilobed or buttock-shaped nuclei with moderate cytoplasm. H) PBS of A case of APL with PML-RARA. I) PBS showing large sized lymphocytes and azurophilic granules indicating PBP-NKLL. J) PBS showing Multiple Auer rods cells in criss-cross pattern indicating AML. (All the images shown are x400; inserts are x1000; BMA and PBS samples were stained by Giemsa and Leishman stains, respectively).

AML: Acute myeloid leukemia, APL: Acute promyelocytic leukemia, BMA: Bone marrow aspirate, NOS: Not otherwise specified, PBS: Peripheral blood smear, s/o: Suggestive of 
Table IV: Immunophenotyping findings in cases of acute leukemias

\begin{tabular}{|c|c|c|c|c|c|}
\hline \multirow[b]{2}{*}{$\begin{array}{l}\text { Type of Acute } \\
\text { Leukemia }\end{array}$} & \multicolumn{5}{|c|}{ Positive markers } \\
\hline & $\begin{array}{c}\text { Non-specific } \\
\text { lineage markers }\end{array}$ & $\begin{array}{c}\text { Lymphoid T-cell } \\
\text { markers }\end{array}$ & $\begin{array}{c}\text { Lymphoid B-cell } \\
\text { markers }\end{array}$ & Myelomonocytic markers & Erythroid markers \\
\hline \multicolumn{6}{|l|}{ ALL } \\
\hline \multicolumn{6}{|l|}{ 1) $T$-ALL } \\
\hline 1a) T-ALL NOS & Tdt $(-$ to $\operatorname{dim}+)$ & $\begin{array}{c}\mathrm{CD} 2 \text { (dim to } \\
\text { mod+), CD3, cCD3, } \\
\text { CD5, CD7 positive }\end{array}$ & CD10 (aberrant+) & - & - \\
\hline
\end{tabular}

2) B-ALL

2a) B-ALL NOS
HLADR, Tdt,

CD34 positive, CD34/HLADR coexpression positive
CD7 (aberrant+),
CD56 (aberrant+)
CD10+, CD19+,

CD10/19 co-

expression+, $\quad$ CD33 (aberrant+)

CD20+, CD22+,

cCD79a+, CD38+

2b) B-ALL RGA

(i) B-ALL with $\mathrm{t}(12 ; 21)$

(p13;q22)-TEL
AML1(ETV6 RUNX1)

(ii) B-ALL with $\mathrm{t}(9 ; 22)$

\section{CD34+}

HLADR+
CD10+, CD19+
$\mathrm{CD} 13+, \mathrm{CD} 33+$

CD13+
(q34;q11.2)-BCR ABL1

CD10+, CD19+

AML

1) AML - RGA

1a) AML with $t(8 ; 21)$

(q22;q22.1) RUNX1

RUNX1T1

1b) APL with PML

1b) AP
RARA
HLADR+, Tdt

(weak+), CD34+
CD25+

CDiot, $\mathrm{CD} 19+$

$\mathrm{CD} 45+\quad \mathrm{CD} 2$ (aberrant+)

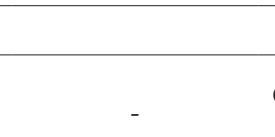

$\mathrm{CD} 13+$

1c) AML with mutated NPM1

1d) AML with biallelic mutations of CEBPA
$\mathrm{CD} 13+, \mathrm{CD} 33+, \mathrm{CD} 117+$, cMPO+, CD15+

CD13+, CD33+, CD117+,

CD64 (mod+), CD11c (-

to weak+), cMPO+, CD14 (weak+), CD15 (weak+)

CD13+, CD33+, CD117+, $\mathrm{CD} 11 \mathrm{~b}+, \mathrm{cMPO}+$

\begin{tabular}{|c|c|c|c|c|}
\hline mutations of CEBPA & CD45+ & & CD38+ & $\mathrm{CD} 11 \mathrm{~b}+, \mathrm{CD} 14+$ \\
\hline 2) AML-MRC & CD34+ & $\begin{array}{l}\text { CD5 (aberrant }+ \text { ), } \\
\text { CD7 (aberrant }+ \text { ), } \\
\text { CD56 (aberrant+) }\end{array}$ & - & $\begin{array}{c}\mathrm{CD} 33+, \mathrm{CD} 117+, \mathrm{CD} 64+, \\
\mathrm{CD} 14+\end{array}$ \\
\hline
\end{tabular}

\section{3) AML - NOS}

3a) AML with minimal HLADR+, CD34+, differentiation CD34/HLADR co-expression+

3b) AML without maturation

3c) AML with
HLADR+, CD34+

CD7 (aberrant+) CD38 (aberrant+) $\mathrm{CD} 13+, \mathrm{CD} 33+, \mathrm{CD} 117+$
cMPO+ maturation HLADR+, CD34+, CD7 (aberrant+), CD45+ CD56 (aberrant+)

CD7 (aberrant+)
CD7 (aberrant+),
CD56 (aberrant+)

CD13+, CD33+, CD117+, $\mathrm{CMPO}+$

3e) Acute monoblastic leukemia

HLADR (dim +$)$, CD45+

CD7 (aberrant+)

CD13+, CD33+, CD117+, CD64+, cMPO+, CD15+ CD13+, CD33+, CD117+, CD64+, CD11b+, $\mathrm{CD} 11 \mathrm{c}+, \mathrm{cMPO}+, \mathrm{CD} 14+$, $\mathrm{CD} 15+$

\begin{tabular}{|c|c|}
\hline $\begin{array}{l}\text { 3d) Acute } \\
\text { myelomonocytic }\end{array}$ & CD45+ \\
\hline
\end{tabular}
CD13+, CD33+, CD64+, $\mathrm{CD} 11 \mathrm{~b}+, \mathrm{CD} 11 \mathrm{c}+$ cMPO+, CD14+, CD15+

3f) Pure erythroid leukemia

CD3+

CD117+

CD71 (Glycophorin A)+, CD36 (early erythroid marker)+, E-cadherin+

AML: Acute myeloid leukemia, ALL: Acute lymphoblastic leukemia, NOS: Not otherwise specified, NK: Natural killer cell, RGA: Recurrent genetic abnormality, MRC: Myelodysplasia-related changes, APL: Acute promyelocytic leukemia, CD: Cluster differentiation, cMPO: Cytoplasmic myeloperoxidase. 
Table V: Distribution of acute leukemia cases according to prognosis

\begin{tabular}{|c|c|c|c|}
\hline Type of Acute Leukemia & $\begin{array}{c}\text { Favorable } \\
\text { prognosis }(n=41)\end{array}$ & Unfavorable prognosis $(n=27)$ & $\begin{array}{c}\text { Mortality } \\
(\mathrm{n}=31)\end{array}$ \\
\hline \multicolumn{4}{|l|}{ ALL } \\
\hline \multicolumn{4}{|l|}{ 1) $\mathrm{T}-\mathrm{ALL}$} \\
\hline 1a) T-ALL NOS & 1 & 4 & 4 \\
\hline 1b) T-ALL NK & - & 1 & 1 \\
\hline \multicolumn{4}{|l|}{ 2) B-ALL } \\
\hline 2a) B-ALL NOS & 8 & $\begin{array}{c}7 \\
\text { (aberrant marker positivity, CNS } \\
\text { involvement, presence of minimal } \\
\text { residual disease after therapy) }\end{array}$ & 7 \\
\hline \multicolumn{4}{|l|}{ 2b) B-ALL RGA } \\
\hline $\begin{array}{l}\text { (i) B-ALL with t(12;21)(p13;q22)-TEL } \\
\text { AML1(ETV6 RUNX1) }\end{array}$ & 3 & - & 0 \\
\hline (ii) B-ALL with $\mathrm{t}(9 ; 22)(\mathrm{q} 34 ; \mathrm{q} 11.2)-\mathrm{BCR}$ ABL1 & - & 1 & 1 \\
\hline
\end{tabular}

AML

1) AML - RGA

1a) AML with $\mathrm{t}(8 ; 21)(\mathrm{q} 22 ; \mathrm{q} 22.1)$ RUNX1 RUNX1T1
6
6

6

1b) APL with PML RARA

1c) AML with mutated NPM1

1d) AML with biallelic mutations of CEBPA

2) $\mathrm{AML}$ - MRC

3) $\mathrm{AML}$ - NOS

\begin{tabular}{llll}
\hline 3a) AML with minimal differentiation & - & 2 & 2 \\
\hline 3d) Acute myelomonocytic leukemia & 3 & 0 & 1 \\
\hline 3e) Acute monoblastic leukemia & 3 & 1 & 1 \\
\hline 3f) Pure erythroid leukemia & - & 1 & 1 \\
\hline 3g) AML without Maturation & - & 2 & 2 \\
\hline 3h) AML with maturation & 9 & - & 4 \\
\hline
\end{tabular}

AML: Acute myeloid leukemia, ALL: Acute lymphoblastic leukemia, NOS: Not otherwise specified, NK: Natural killer cell, RGA: Recurrent genetic abnormality, MRC: Myelodysplasia-related changes, APL: Acute promyelocytic leukemia.

\section{DISCUSSION}

The present study was conducted to diagnose and classify AL cases according to the WHO (2016) Classification and study their clinicopathological profiles (9). Sixty-eight AL cases were studied for a period of 2 years. AML was more commonly diagnosed than ALL, similar to previous studies $(5,6)$. ALL was found to be more common in children (aged 1-14 years) and AML in adults (aged $>30$ years) in concordance with the findings of Dores et al. and others $(7,12-17)$. The presenting signs and symptoms also found resonance with these studies (12-17). Fever was the most common complaint in both the leukemias, similar to Kumar et al., Ghosh et al., and others (72-89\%) (12-16). This was most likely associated with granulocytopenia and concomitant infections $(17,18)$. Generalized weakness and 
bleeding manifestations were also similar to these studies (12-16). Gingival bleeding was not seen in any of the ALL cases but was present in AML cases, akin to the studies by Ghosh et al. (23\%), Preethi CR (25\%), and Sultan et al. (22\%). This is suggested to be due to thrombocytopenia and neutropenia (14-16). The most common presenting sign in both ALL and AML was pallor followed by hepatosplenomegaly, similar to the above-mentioned studies, likely related to anemia and organ infiltration, respectively (12-16). The increased peripheral smear blast cell \% (68\% in ALL and 61\% in AML) also mirrors that seen by Kumar et al. (85\% in ALL) and Ghosh et al. (57.6\% in AML). This correlates to overproduction and blood infiltration of immature white blood cells (12-14).

\section{Acute Lymphoblastic Leukemia (ALL)}

B-cell ALL (B-ALL) was found to be more common than T-cell ALL (T-ALL), in agreement with the prevalence noted by Kumar et al. (63\%) (12). Most B-ALL blasts showed CD10 and CD19 positivity. B-ALL not otherwise specified (NOS) revealed CD56 aberrancy, a normal karyotype, and posterior reversible encephalopathy syndrome, with death reported within 5 days of admission. This is in agreement with the findings of Swerdlow et al. and Arber et al. who stated that cranial nervous system (CNS) involvement leads to an adverse prognosis in ALL patients $(9,19)$. B-ALL cases with recurrent genetic abnormality (RGA) $\mathrm{t}(12 ; 21)(\mathrm{p} 13 ; \mathrm{q} 22)$ TEL-AML1 (ETV6-RUNX1) revealed blast cell positivity for CD19, CD10, CD34, and CD13 but were typically negative for CD20, CD9, CD66c. These patients achieved molecular remission with a cure rate of $>90 \%(9,19,20)$. B-ALL RGA $(9 ; 22)$ BCR-ABL1 showed a higher incidence in adults with the blasts cells typically showing high-frequency expression of CD25. Despite imatinib therapy, mortality was recorded within 3 months from diagnosis. They are usually associated with the worst prognosis among all B-ALL RGA cases $(9,19)$. T-ALL cases revealed CD2 and CD7 positivity. T-ALL natural killer cell leukemia (T-ALL NK), diagnosed in a 50-year old male, had an immunophenotypic picture showing CD45 bright+ as well as cytoplasmic myeloperoxidase (cMPO)negative blasts and marked leukocytosis with 85-90\% large-sized lymphoid cells (having high $\mathrm{N}: \mathrm{C}$ ratio, clumped chromatin and cytoplasmic granules with 1-2 prominent gated nucleoli). Death was recorded within a month from diagnosis. T-LL NOS also presented with mostly an unfavorable prognosis. Other studies have also found T-ALL NK to have an extremely poor prognosis $(9,20,21)$.

\section{Acute Myeloid Leukemia (AML)}

The present study found AML-NOS to be the most common type of AML, unlike Nunes et al. who found AML-RGA to be the most prevalent. However, the distribution of AMLRGA subtypes mirrored the works of Nunes et al. (22). AML-NOS was a diagnosis of exclusion, made for cases that cytogenetically did not fulfill the criteria for other AML subtypes, as per the WHO classification (9). However, cytogenetic studies were not performed by Ghosh et al. and Preethi CR, and instead the FAB classification (1976) was employed (8). They found that a small percentage of cases remained, and these were categorized under AML M3 as per FAB classification, which is now categorized as acute promyelocytic leukemia (APL) with PML/RARA under AML-RGA $(8,14,15)$. It was noted that the WHO (2017) (9) AML-NOS subcategory closely matched the FAB (1976) AML with maturation (FAB M2) subcategory $(8,14,15)$. The presence of APL with PML-RARA, with concomitant disseminated intravascular coagulation (DIC) and CNS involvement, typically led to a very poor prognosis $(9,19,23)$. An increase in promyelocytes on peripheral smear and bone marrow aspirate myelogram was seen, along with the absence of megakaryocytes. Hypergranular variants had multiple Auer rods in the cytoplasm of myeloblasts and/or progranulocytes. Cases of AML-RGA $\mathrm{t}(8 ; 21)$ (q22;q22)RUNx1-RUNX1T1 with tuberculosis (TB) required stopping anthracylines and cyclophosphamide for 3 weeks due to a risk of flaring up of TB, but with chances of increase in mortality. Hence, careful anti-leukemic therapy was continued after starting anti-tubercular therapy as early as possible $(9,19,23)$. AML with mutated NPM1 was diagnosed in older individuals with the blast cells typically negative for CD34. Nucleophosmin (NPM) is a surrogate marker for this gene mutation, seen in about $33 \%$ of AML cases, with the morphology resembling acute myelomonocytic/monocytic leukemia and has a good prognosis. AML with biallelic mutations of CCAAT enhancer binding protein alpha (CEBPA) was typically associated with a normal $\mathrm{Hb}$ level, normal karyotype, and higher blast cell count with a good response to induction chemotherapy $(9,19,24,25)$. According to Walter et al., AML-NOS patients corresponded to the FAB M0 category, known to have significantly worse outcomes than non-M0 cases, similar to the present study (26).

The present study establishes the WHO (2016) classification as a practically useful system for diagnosing the various types of AL, primarily with a focus of providing targeted 
therapy. Cytogenetics is one of the most important diagnostic parameters as recurrent genetic aberrations have provided insights into the molecular mechanisms of leukemogenesis. The uniformity in categorizing these diseases, afforded by this classification system, permits the use of immunotherapy such as specific targeting of $\mathrm{CD}$ expression especially in patients failing induction therapies. Lately, monoclonal antibody therapy has become a significant component of the treatment protocol, for example the use of Gemtuzumab for CD33-positive AML. Stem cell transplantation is also required in many cases receiving chemotherapy and radiotherapy as it helps to replenish their bone marrow reservoir with normal hematopoietic stem cells (27).

This study has its limitations in being a single-center, crosssectional study with a limited sample size. Multicentric, prospective studies with larger sample size and longer follow-up periods are encouraged to validate the results.

In conclusion, the application of revised 4th edition WHO 2016 classification of acute leukemias confers uniformity in reporting of acute leukemia cases, which aids in treatment by using targeted therapies and helps in prediction of prognosis. The categorization of acute leukemia cases in favorable and unfavorable prognosis groups tells us about the future outcome of cases, and findings of this study show that the unfavorable prognosis group has a dismal prognosis. Overall, the revised 4th edition WHO 2016 classification is very objective, therapy oriented and the need of the hour.

\section{ACKNOWLEDGMENT}

The authors are thankful to Dr. Garima Agrawal, Dr. Nikita Vohra, Dr. Dhiraj Shukla, Dr. Sourish Hota, Dr. Chintan Sangoi, Nitin H Patel, Aruna Sangoi, and Mayuri Patel for extending their help and support in this research work.

\section{CONFLICT of INTEREST}

The authors declare no conflict of interest.

\section{FUNDING}

The study was not funded by any government or private funding bodies.

\section{AUTHORSHIP CONTRIBUTIONS}

Concept: GNP, RG, SK, Design: SK, Data collection or processing: GNP, RG, Analysis or Interpretation: GNP, RG, AG, RMO, Literature search: AG, RMO, SK, Writing: GNP, AG, RMO, Approval: GNP, RG, AG, RMO, SK.

\section{REFERENCES}

1. Firkin F, Chesterman C, Rush B, Pennigton D, editors. De Gruchy's Clinical Haematology in medical practice. 5th ed. London: Blackwell Scientific Publication;1998.236-76.

2. Ward G. The infective theory of acute leukemia. Br J Child Dis. 1917;14:10-20.

3. Shysh AC, Nguyen LT, Guo M, Vaska M, Naugler C, RashidKolvear F. The incidence of acute myeloid leukemia in Calgary, Alberta, Canada: A retrospective cohort study. BMC Public Health. 2017;18:94.

4. Solomon B, Parihar N, Ayodele L, Hughes M. Global incidence and prevalence of acute lymphoblastic leukemia: A 10-year forecast. J Blood Disord Transfus. 2017;8:5(Suppl).

5. Statistics by country for acute myeloid leukemia. Available from: https://www.rightdiagnosis.com/a/acute_myeloid_leukemia/ stats-country.htm.

6. Statistics by country for acute lymphocytic leukemia. Available from: https://www.rightdiagnosis.com/a/acute_lymphocytic_ leukemia/stats-country.html .

7. Dores GM, Devesa SS, Curtis RE, Linet MS, Morton LM. Acute leukemia incidence and patient survival among children and adults in the United States, 2001-2007. Blood. 2012;119:34-43.

8. Bennet JM, Catovsty D, Daniel MT, Fandrin G, Galton DA Gralnick HR, Sultan C. Proposals for classification of the acute leukaemias. French-American-British (FAB) co-operative group. Br J Haematol. 1976;33:451-8.

9. Swerdlow S, Campo E, Harris N, Jaffe E, Phileri S, Stein H, editors. WHO classification of tumors of haematopoietic and lymphoid tissues. Revised 4th ed. Lyon, France: IARC;2017.

10. Muniraj F. Classification of acute leukemias - past, present, and future. IJSS Case Reports and Reviews. 2015;1:61-6.

11. Pangalis GA. Contribution of cytochemistry in leukemia. In: Polliack A, editor. Human Leukemias. Developments in oncology series. Boston, MA: Springer; 1984.3-14.

12. Kumar S, Anand S, Sahu TP. Clinico-hematological profile of paediatric patient admitted with acute leukemia in tertiary care centre of central India. Indian J Child Health. 2017;3:308-10.

13. Nayyar A, Ahmed S. Acute lymphoblastic leukaemia: Clinicohaematological features, laboratory characteristics and prognostic factors: A single center experience. J Islam Int Med Coll. 2013;8:83-8

14. Ghosh S, Shinde SC, Kumaran GS, Sapre RS, Dhond SR, Badrinath Y, Ansari R, Kumar A, Mahadik S, Chougule AB, Nair CN. Haematologic and immunophenotypic profile of acute myeloid leukemia: An experience at Tata Memorial Hospital. Indian J Cancer. 2003;40:71-6.

15. Preethi CR. Clinico-hematological study of acute myeloid leukemias. J Clin Diagn Res. 2014;8:14-7.

16. Sultan S, Zaheer HA, Irfan SM, Ashar S. Demographic and clinical characteristics of adult acute myeloid leukemia - Tertiary care experience. Asian Pac J Cancer Prev. 2016;17:357-60.

17. Goodall PT, Vosti KL. Fever in acute myelogenous leukemia. Arch Intern Med. 1975;135:1197-203. 
18. Wolk JA, Stuart MJ, Stockman JA 3rd, Oski FA. Neutropenia, fever, and infection in children with acute lymphocytic leukemia. Am J Dis Child. 1977;131:157-8.

19. Arber DA, Brunning RD, Le Beau MM et al. Acute myeloid leukemias with recurrent genetic abnormalities. In: Swerdlow S, Campo E, Harris N, Jaffe E, Phileri S, Stein H, editors. WHO classification of tumors of haematopoietic and lymphoid tissues. Revised 4th ed. Lyon: IARC;2017.

20. Borowitz MJ, Chan JKC, Downing JR, Le Beau MM, Arber DA. B-lymphoblastic leukemia/lymphoma with recurrent genetic abnormalities. In: Swerdlow SH, Campo E, Harris NL, Jaffe ES, Phileri SA, Stein H, Thiele J, editors. WHO classification of tumours of haematopoietic and lymphoid tissues. Revised 4th ed. Lyon:IARC Press; 2017. 203-9.

21. Borowitz MJ, Chan JKC, Downing JR, Le Beau MM, Arber DA. T-lymphoblastic leukemia/lymphoma with recurrent genetic abnormalities. In: Swerdlow S, Campo E, Harris N, Jaffe E, Phileri S, Stein H, editors. WHO classification of tumours of haematopoietic and lymphoid tissues. Revised 4th ed. Lyon: IARC Press; 2017. 209-13.

22. Nunes AL, Paes CA, Murao M, Viana MB, Oliveira BMD. Cytogenetic abnormalities, WHO classification, and evolution in children and adolescents with acute myeloid leukemia. Hematol Transfus Cell Ther. 2019;41:236-43.
23. Golomb HM, Rowley JD, Vardiman JW, Testa JR, Butler A. "Microgranular" acute promyelocytic leukemia: A distinct clinical, ultrastructural, and cytogenetic entity. Blood. 1980;55:253-9.

24. Verhaak RG, Goudswaard CS, van Putten W, Bijl MA, Sanders MA, Hugens W, Uitterlinden AG, Erpelinck CAJ, Delwel R, Löwenberg B, Valk PJM. Mutations in nucleophosmin (NPM1) in acute myeloid leukemia (AML): Association with other gene abnormalities and previously established gene expression signatures and their favorable prognostic significance. Blood. 2005; 106:3747-54.

25. Dufour A, Schneider F, Metzeler KH, Hoster E, Schneider S, Zellmeier E, Benthaus T, Sauerland MC, Berdel WE, Büchner T, Wörmann B, Braess J, Hiddemann W, Bohlander SK, Spiekermann K. Acute myeloid leukemia with biallelic CEBPA gene mutations and normal karyotype represents a distinct genetic entity associated with a favorable clinical outcome. J Clin Oncol. 2010;28:570-7.

26. Walter RB, Othus M, Burnett AK, Löwenberg B, Kantarjian HM, Ossenkoppele GJ, Hills RK, van Montfort KGM, Ravandi F, Evans A, Pierce SR, Appelbaum FR, Estey EH. Significance of FAB subclassification of "acute myeloid leukemia, NOS" in the 2008 WHO classification: Analysis of 5848 newly diagnosed patients. Blood. 2013;121:2424-31.

27. Mehranfar S, Zeinali S, Hosseini R, Mohammadian M, Akbarzadeh A, Feizi AHP. History of leukemia: Diagnosis and treatment from beginning to now. GMJ. 2017,6:12-22. 